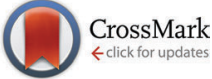

Cite this: New J. Chem., 2016, 40, 9060

Received (in Montpellier, France) 27th April 2016,

Accepted 22nd July 2016

DOI: 10.1039/c6nj01334a

www.rsc.org/njc

\section{Weak interactions within nitryl halide heterodimers $\dagger$}

\author{
David Quiñonero, ${ }^{\text {a }}$ Antonio Bauzá, ${ }^{a}$ Goar Sánchez-Sanz, ${ }^{* b}$ Cristina Trujillo, ${ }^{c}$ \\ Ibon Alkorta ${ }^{d}$ and José Elguero ${ }^{d}$
}

\begin{abstract}
A theoretical study of nitryl halide heterodimers has been carried out using SCS-RI-MP2 and CCSD(T) at the complete basis set (CBS) calculations. For this purpose, 66 heterodimers have been characterized as minima and arranged in six groups depending on the interactions involved and their geometrical arrangements. The CCSD(T)/CBS interaction energies vary between -0.6 and $-11.1 \mathrm{~kJ} \mathrm{~mol}^{-1}$. The heavier the halogen atoms, the larger the interaction energies. Natural bond orbital (NBO) and "atoms-in-molecules" (AIM) theories were then used to analyze the complexes, confirming the presence of halogen, chalcogen, and $\pi$-hole interaction bonds. The largest charge-transfer energy contributions were found for halogen bonded complexes (up to $29.1 \mathrm{~kJ} \mathrm{~mol}^{-1}$ ). Furthermore, the physical nature of the interactions was studied using symmetry-adapted perturbation theory (SAPT) calculations, and it was concluded that dispersion was the major source of attraction, although electrostatics is important in halogen bonded complexes.
\end{abstract}

\section{Introduction}

Non-covalent interactions between molecules have been shown to be of great importance in supramolecular chemistry, molecular biology, and even in materials science. ${ }^{1}$ Among the noncovalent interactions, the hydrogen bond (HB) is probably the most important. However, the number of non covalent interactions (also known as weak interactions) is not only limited to the HB but there is a broad range and type of those interactions including halogen bonds, ${ }^{2}$ hydride bonds ${ }^{3}$ tetrels,${ }^{4-6}$ chalcogenchalcogen interactions $^{7-10}$ and in the last decade, pnictogen interactions. ${ }^{11-36}$

The electrostatic nature of some of these interactions, in particular halogen, chalcogen and pnictogen interactions, has been explained by the $\sigma$-hole concept developed by Politzer. ${ }^{37-39}$ The term $\sigma$-hole refers to the electron-deficient outer lobe of a p orbital involved in forming a covalent bond, in particular when one of the atoms is very electronegative. In the specific cases in which the positive electrostatic potential area is located perpendicular to a portion of a molecular plane, this region is called a $\pi$-hole. One example of an intermolecular weak interaction

\footnotetext{
${ }^{a}$ Departament de Química, Universitat de les Illes Balears, Crta. de Valldemossa km 7.5, 07122 Palma de Mallorca, Spain. E-mail: david.quinonero@uib.es

${ }^{b}$ School of Chemistry, University College Dublin, Belfield, Dublin 4, Ireland. E-mail: goar.sanchez@ucd.ie

${ }^{c}$ School of Chemistry, Trinity Biomedical Sciences Institute, Trinity College Dublin, 152-160 Pearse St., Dublin 2, Ireland

dInstituto de Química Médica, CSIC, Juan de la Cierva, 3, E-28006 Madrid, Spain

$\dagger$ Electronic supplementary information (ESI) available. See DOI: 10.1039/c6nj01334a
}

through the $\pi$-hole can be found in nitryl derivatives in which the nitrogen atom acts as an electron acceptor and may interact with electron donors. Furthermore, these types of interactions are also simultaneously classified as orthogonal and $\pi$-hole interactions. $^{40,41}$

In recent decades, major interest has been shown towards the so-called reservoir compounds in the atmosphere. A great effort has been devoted to studying and understanding their molecular properties including isomerization processes and the role of their related formation reactions in stratospheric ozone depletion cycles ${ }^{42,43}$ and tropospheric halogen activation. ${ }^{44}$ Nitryl halides $\left(\mathrm{XNO}_{2}\right)$, have been suggested to be examples of such reservoir species. ${ }^{45,46}$ The potential interactions of the $\mathrm{XNO}_{2}$ with $\mathrm{NH}_{3},{ }^{47} \mathrm{NCH}$ and $\mathrm{CNH}^{48}$ molecules as electron donors in the $\sigma$ - and $\pi$-hole regions have been previously studied with $\mathrm{XNO}_{2}$ and other nitryl derivatives. ${ }^{49,50}$ Experimental evidence of non-covalent interactions involving nitryl moieties have been recently reported by Roy et $a l .{ }^{51}$ In the present work, the attention has been focused on the nature of the non-covalent interactions found between nitryl halide heterodimers. Thus, the chemical groups attached to the nitryl moiety have been expanded along the halogen series, with bromine $(\mathrm{Br})$, chlorine $(\mathrm{Cl})$, fluorine $(\mathrm{F})$ and iodine (I) atoms.

\section{Computational details}

All the geometries of the complexes formed by two $\mathrm{XNO}_{2}(\mathrm{X}=\mathrm{F}$, $\mathrm{Cl}, \mathrm{Br}$ or I) monomers were fully optimized using second order 
Møller-Plesset perturbation theory (MP2) with the aug-cc-pVTZ basis set. ${ }^{52,53}$ For heavy atoms, such as I, ${ }^{54}$ the aug-cc-pVTZ-PP pseudo potential basis set was used. Harmonic vibrational frequencies were computed at the same level used in order to verify that the structures obtained corresponded to local minima.

For the preliminary calculations geometry optimizations were carried out using the spin-component scaled MP2 method (SCS-RI-MP2) with the aug-cc-pVTZ basis set and the energies were refined by using the couple cluster single double (triple)/ complete basis set CCSD(T)/CBS method. The CCSD(T) technique provides reliable interaction energies only if they are combined with extended atomic orbital (AO) basis sets, and the larger the basis set, the better the interaction energies that result. Because of the rather strong dependence of the interaction energy on the $\mathrm{AO}$ basis set size, it is recommended that the relevant calculations be performed at the CBS limit. Different extrapolation schemes have been introduced and the scheme of Helgaker et al. ${ }^{55,56}$ has become the most widely used. Here, the Hartree-Fock (HF) and correlation (MP2) energies are extrapolated separately as follows:

$$
\begin{gathered}
E_{\mathrm{X}}^{\mathrm{HF}}=E_{\mathrm{CBS}}^{\mathrm{HF}}+A e^{-\alpha \mathrm{X}} \\
E_{\mathrm{X}}^{\mathrm{MP} 2}=E_{\mathrm{CBS}}^{\mathrm{MP} 2}+B X^{-3} \\
E_{\mathrm{CBS}}^{\mathrm{CCSD}(\mathrm{T})}=E_{\mathrm{CBS}}^{\mathrm{HF}}+E_{\mathrm{CBS}}^{\mathrm{MP} 2}+\left(E^{\mathrm{CCSD}(\mathrm{T})}-E^{\mathrm{MP} 2}\right)_{\mathrm{AVTZ}}
\end{gathered}
$$

where $E_{\mathrm{X}}$ and $E_{\mathrm{CBS}}$ are the energies for the basis set with the largest angular momentum $\mathrm{X}$ and for the complete basis set, respectively. The $\operatorname{CCSD}(\mathrm{T}) / \mathrm{CBS}$ level can be attained via a separate extrapolation of the MP2 and higher-order correlation energies towards the basis-set limit (eqn (3)). Here, each of the components is differently sensitive to the AO basis set: the MP2 correlation energy is the more slowly converging, and the larger the basis set used in the extrapolation, the better. In our case we have used a two point extrapolation scheme by using the aug-cc-pVTZ and the aug-cc-pVQZ basis sets. The third term, called the $\operatorname{CCSD}(\mathrm{T})$ correction term $\left(\Delta E^{\mathrm{CCSD}(\mathrm{T})}-\Delta E^{\mathrm{MP} 2}\right)$, is determined as the difference between the $\operatorname{CCSD}(\mathrm{T})$ and MP2 energies and converges much faster than the MP2 correlation energy, the second term. The use of such a term is possible, because the MP2 and CCSD(T) energies converge with basis-set size in a very similar way; consequently, its difference is much less basis-set dependent and much smaller basis sets can be applied. In our case we have used the aug-cc-pVTZ basis set to compute the $\operatorname{CCSD}(\mathrm{T})$ correction. All of the geometry optimization described herein were carried out by using TURBOMOLE version 7.0 and CBS calculations were computed by using MOLPRO program.

Binding energies were obtained as the difference between the energy of the complex and the energy of the geometry optimized isolated nitryl halides.

The bonding characteristics were analyzed by means of the atoms in molecules (AIM) theory.

For this purpose the most relevant bond critical points (BCP) were located and the electron density at each of them was evaluated, using the AIMALL programs. ${ }^{57}$ All the interactions were characterized by the formation of a BCP between the atoms involved that are connected by the corresponding bond paths.

The natural bond orbital (NBO) method ${ }^{58}$ was employed to evaluate the atomic charges using the NBO 3.1 program, included within the Gaussian 09 program, and to analyze charge-transfer interactions between occupied and empty orbitals.

The symmetry adapted perturbation theory (SAPT $)^{59}$ method allowed for the decomposition of the interaction energy into different terms related to physically well-defined components, such as those arising from electrostatic, exchange, induction, and dispersion terms. The interaction energy $\left(E_{\text {int }}\right)$ can be expressed within the framework of the SAPT method as:

$$
E_{\mathrm{int}}=E_{\mathrm{el}}^{(1)}+E_{\mathrm{exch}}^{(1)}+E_{\mathrm{l}}^{(2)}+E_{\mathrm{D}}^{(2)}
$$

where $E_{\mathrm{el}}^{(1)}$ is the electrostatic interaction energy of the monomers each one with its unperturbed electron distribution; $E_{\mathrm{exch}}^{(1)}$ is the first-order exchange energy term; $E_{\mathrm{i}}^{(2)}$ denotes the second-order induction energy arising from the interaction of permanent multipoles with induced multipole moments and chargetransfer contributions, plus the change in the repulsion energy induced by the deformation of the electronic clouds of the monomers; $E_{\mathrm{D}}^{(2)}$ is the second-order dispersion energy, which is related to the instantaneous multipole-induced, multipole moment interactions plus the second-order correction for coupling between the exchange repulsion and the dispersion interactions.

The density fitting-density functional theory-SAPT (DF-DFTSAPT) formulation has been used to investigate interaction energies. In this approach, the energies of the interacting monomers are expressed in terms of orbital energies obtained from Kohn-Sham DFT. ${ }^{60,61}$ In addition to the terms listed in eqn (4), a HF correction term $\delta(\mathrm{HF})$, which takes into account higher-order induction and exchange corrections, has been included. $^{62}$ The DF-DFT-SAPT calculations were performed using the PBE0/aug-cc-pVTZ/aug-cc-pVTZ-PP computational method. ${ }^{63}$ Asymptotic corrections for this function were considered using the experimental values of the ionization potentials for nitryl fluoride $\left(\mathrm{NO}_{2} \mathrm{~F}\right),{ }^{64}$ and nitryl chloride $\left(\mathrm{NO}_{2} \mathrm{Cl}\right) \cdot{ }^{65}$ In the remaining cases, the calculated values of the MP2/aug-cc-pVTZ computational values have been used. As auxiliary fitting basis set the JK-fitting basis of Weigend ${ }^{66}$ was employed. The cc-pVQZ JK-fitting basis was used for all atoms. For the intermolecular correlation terms, i.e., the dispersion and exchangedispersion terms, the related aug-cc-pVTZ MP2-fitting basis of Weigend et al., ${ }^{67}$ was employed. All these calculations were carried out using the MOLPRO quantum chemistry software. ${ }^{68}$

In order to provide a clear nomenclature, the complexes found have been sorted as follows: $\mathbf{X Y}_{\mathbf{n z}}$, where $\mathrm{X}$ and $\mathrm{Y}$ ( $\mathrm{X}, \mathrm{Y}=\mathrm{F}, \mathrm{Cl}, \mathrm{Br}$, or I) correspond to the halogen atoms of the interacting nitryl halides $\left(\mathrm{XNO}_{2}\right.$ or $\left.\mathrm{YNO}_{2}\right), n(n=1-6)$ is an ordinal which indicates the type of complex, and $\mathrm{z}(\mathrm{z}=\mathrm{a}, \mathrm{b})$ is an identifier which discriminates between two different configurations in the same type of complex. For example, $\mathbf{F C l}_{\mathbf{3 a}}$ corresponds to a $\mathrm{FNO}_{2}: \mathrm{ClNO}_{2}$ complex in which $\mathrm{F}$ is the halogen electron donor moiety, whereas in $\mathbf{F C l}_{\mathbf{3 b}}$, chlorine is the atom interacting in the Lewis base moiety. 

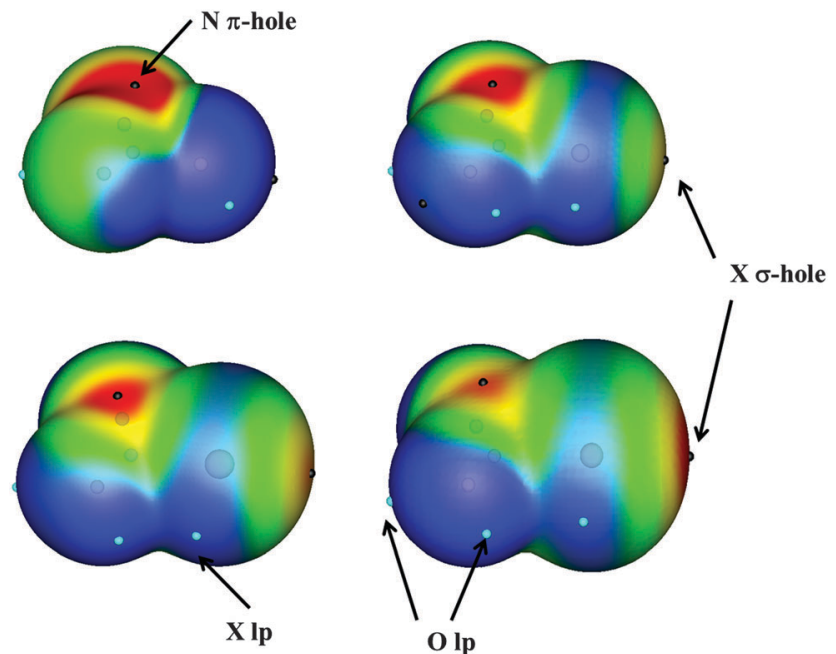

Fig. 1 Molecular electrostatic potential on the 0.001 a.u. electron density isosurface of $\mathrm{NO}_{2} \mathrm{X}(\mathrm{X}=\mathrm{F}, \mathrm{Cl}, \mathrm{Br}$, or I) monomers. MEP values colour scheme: red $>0.0350>$ yellow $>0.015>$ green $>0.00$ blue $<0.00$. Maxima and minima values of MEP are represented by black and cyan dots, respectively.

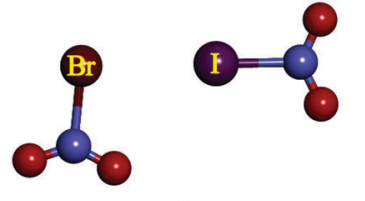

1a

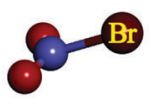

3a
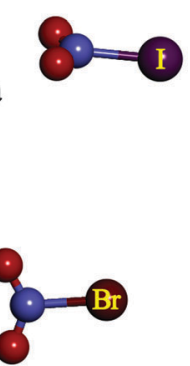

5a

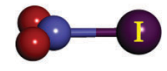

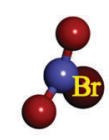

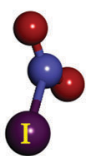

$2 \mathbf{a}$
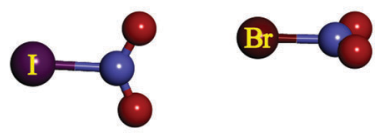

$4 \mathbf{a}$
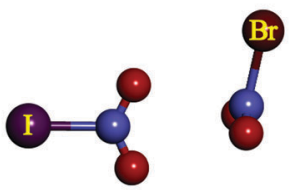

6a
Fig. 2 Summary of the geometries of the 1-6 complexes under study exemplified by the $\mathrm{Brl}_{\mathrm{a}}$ complexes.

\section{Results and discussion}

\section{Structure and energetics}

Monomers have been extensively studied in the literature, ${ }^{4-50}$ and therefore will not be discussed in the present paper. However, it is worth mentioning that all the $\mathrm{XNO}_{2}$ present a $\pi$-hole over the $\mathrm{N}$ atom with molecular electrostatic potential
(MEP) values of 154.9, 128.7, 119.5 and $75.4 \mathrm{~kJ} \mathrm{~mol}^{-1}$ for $\mathrm{X}=\mathrm{F}$, $\mathrm{Cl}, \mathrm{Br}$, and I, respectively, (Fig. 1). ${ }^{50}$ An additional $\sigma$-hole is observed in the halogen atoms along the $\mathrm{X}-\mathrm{N}$ axis with MEP values of $64.9,90.8$ and $129.7 \mathrm{~kJ} \mathrm{~mol}^{-1}(\mathrm{X}=\mathrm{Cl}, \mathrm{Br}$ and I, respectively), with the exception of $\mathrm{FNO}_{2}$ in which it was not found. So those two regions with positive values of MEP will be susceptible to a nucleophile attack. However, negative regions corresponding to halogen and oxygen lone pairs were also described, and therefore, they will act as electron donor regions in the nucleophile attacks. ${ }^{50}$

A total of 66 heterodimer complexes have been found: 10 for each of the FCl, FBr and FI families and another 12 for each of the ClBr, ClI, and BrI families. Their Cartesian coordinates and molecular graphs are summarized in Table S1 (ESI $\dagger$ ), and their geometries are depicted in Fig. 2.

Complexes $\mathbf{X Y}_{\mathbf{1 a}}$ correspond to those in which an $\mathrm{X}$ atom is located pointing towards the $\sigma$-hole of $Y$, whereas in $\mathbf{X Y}_{\mathbf{1 b}}$, the opposite orientation is observed. Complexes $\mathbf{X Y}_{\mathbf{2 a}}$ and $\mathbf{X Y}_{\mathbf{2 b}}$ show similar structures, in which the halogen atom of one of the molecules is facing the $\mathrm{N}$ atom of the other and vice versa. The main difference between both $\mathbf{X Y}_{\mathbf{2}}$ and $\mathbf{X Y}_{\mathbf{2 b}}$ is that in the former complexes, the structures are asymmetrical, whereas in the latter complexes $C_{\mathrm{s}}$ symmetry is found with a plane containing both $\mathrm{X}-\mathrm{N}$ and $\mathrm{Y}-\mathrm{N}$ bonds. $\mathbf{X Y}_{\mathbf{3 a}}$ corresponds to those structures with both interacting molecules parallel one to each other, i.e., their molecular planes are almost parallel, and $\mathrm{X}$ is acting as an electron donor and the $\mathrm{N}$ of the $\mathrm{YNO}_{2}$ molecule is acting as a Lewis acid. $\mathbf{X Y}_{\mathbf{3 b}}$ is similar to $\mathbf{X Y}_{\mathbf{3 a}}$ but in the former complexes $\mathbf{Y}$ is the electron donor. $\mathbf{X Y}_{\mathbf{4 a}}$ and $\mathbf{X Y}_{\mathbf{4 b}}$ complexes show one of the $\mathrm{O}$ atoms of the $\mathrm{YNO}_{2}$ moiety (or $\mathrm{XNO}_{2}$ ) pointing towards the $\mathrm{X}$ (or $\mathrm{Y}$ ) $\sigma$-hole, respectively. $\mathbf{X Y}_{\mathbf{5 a}}$ and $\mathbf{X Y}_{\mathbf{5 b}}$ are similar to $\mathbf{X Y}_{\mathbf{3 a}}$ and $\mathbf{X \mathbf { Y } _ { \mathbf { 3 b } }}$ but in the former complexes both molecular planes are perpendicular to each other. Finally, complexes $\mathbf{X Y}_{\mathbf{6 a}}$ are those in which oxygen atoms belonging to $\mathrm{YNO}_{2}$ are directly over the $\mathrm{N} \pi$-hole of the $\mathrm{XNO}_{2}$ molecule with both molecular planes perpendicular to each other, whereas in $\mathbf{X Y}_{\mathbf{6 b}}$ the opposite is observed. It is worth noting that complexes $\mathbf{1 b}$ and $\mathbf{4 a}$ were not found for the $\mathbf{F C l}, \mathbf{F B r}$ and $\mathbf{F I}$ families because no $\sigma$-hole was found near the $\mathrm{F}$ atom in the $\mathrm{FNO}_{2}$ molecule. Similar arrangements of the monomers were also found in the $\mathrm{XNO}_{2}$ homodimers in previous research, ${ }^{50}$ however, the number and complexity of the heterodimers are much larger than for the homodimers.

The interaction energies, $E_{\mathrm{b}}$, at $\operatorname{CCSD}(\mathrm{T}) / \mathrm{CBS}$ (see computational details) of all 66 complexes are shown in Table 1. The complex with the highest interaction energy corresponds to $\mathbf{B r I}_{4 \mathbf{b}}\left(-11.1 \mathrm{~kJ} \mathrm{~mol}^{-1}\right)$ whereas the smallest one is found for $\mathbf{F B r}_{\mathbf{4 b}}\left(-0.6 \mathrm{~kJ} \mathrm{~mol}^{-1}\right)$. In general, the energy differences between "a" or "b" complexes within the same configuration is relatively small varying from $0.0-0.1 \mathrm{~kJ} \mathrm{~mol}^{-1}\left(\mathbf{C l B r}_{5 \mathbf{a}-5 \mathbf{b}}\right.$ and $\mathbf{C l B r}_{3 \mathbf{a}-3 \mathbf{b}}$ ) up to $2.4 \mathrm{~kJ} \mathrm{~mol}^{-1}$ in the $\mathbf{C l I}_{4 \mathbf{a}-4 \mathbf{b}}$ complexes. Considering the interaction energy range for each family of compounds, FCl $\left(-9.0\right.$ to $\left.-5.2 \mathrm{~kJ} \mathrm{~mol}^{-1}\right), \mathbf{F B r}\left(-4.2\right.$ to $\left.-0.6 \mathrm{~kJ} \mathrm{~mol}^{-1}\right)$, FI $\left(-9.4\right.$ to $\left.-6.4 \mathrm{~kJ} \mathrm{~mol}^{-1}\right)$, $\mathbf{C l B r}\left(-5.5\right.$ to $\left.-2.1 \mathrm{~kJ} \mathrm{~mol}^{-1}\right)$, ClI $(-10.4$ to $\left.-7.0 \mathrm{~kJ} \mathrm{~mol}^{-1}\right)$ and $\mathbf{B r I}\left(-11.1\right.$ to $\left.-9.4 \mathrm{~kJ} \mathrm{~mol}^{-1}\right)$, the largest interaction energies are observed for iodine containing compounds, whereas those with bromine (with the exception of BrI) 
Table 1 Interaction energies $\left(E_{\mathrm{b}}\right.$, in $\left.\mathrm{kJ} \mathrm{mol}^{-1}\right)$ of the 66 complexes studied at the CCSD(T)/CBS level of theory

\begin{tabular}{|c|c|c|c|c|c|c|c|c|c|}
\hline & Compound & $E_{\mathrm{b}} / \mathrm{CBS}$ & Compound & $E_{\mathrm{b}} / \mathrm{CBS}$ & & Compound & $E_{\mathrm{b}} / \mathrm{CBS}$ & Compound & $E_{\mathrm{b}} / \mathrm{CBS}$ \\
\hline & $2 a$ & -8.1 & $2 \mathbf{b}$ & -7.6 & & $2 a$ & -5.5 & $2 \mathbf{b}$ & -4.8 \\
\hline & $3 a$ & -7.9 & $3 \mathbf{b}$ & -6.3 & & $3 \mathbf{a}$ & -5.2 & $3 \mathbf{b}$ & -5.1 \\
\hline & $5 a$ & -8.4 & $5 b$ & -9.0 & & $5 a$ & -5.0 & $5 b$ & -5.0 \\
\hline & $6 a$ & -8.7 & $6 b$ & -8.0 & & $6 a$ & -5.1 & $6 b$ & -4.9 \\
\hline & $3 a$ & -2.9 & $3 \mathbf{b}$ & -2.1 & & $3 a$ & -9.2 & $3 \mathbf{b}$ & -10.4 \\
\hline & $4 a$ & - & $4 b$ & -0.6 & & $4 a$ & -7.9 & $4 \mathbf{b}$ & -10.3 \\
\hline & $5 a$ & -3.2 & $5 b$ & -4.2 & & $5 a$ & -9.4 & $5 \mathbf{b}$ & -9.2 \\
\hline & $6 a$ & -4.1 & $6 b$ & -2.9 & & $6 a$ & -10.3 & $6 b$ & -9.3 \\
\hline \multirow[t]{2}{*}{ FI } & $1 \mathrm{a}$ & -6.8 & $1 b$ & - & BrI & $1 \mathrm{a}$ & -10.6 & $1 b$ & -9.4 \\
\hline & $2 a$ & -7.9 & $2 \mathbf{b}$ & -7.5 & & $2 a$ & -10.5 & $2 \mathbf{b}$ & -10.0 \\
\hline
\end{tabular}

present the smallest $E_{\mathrm{b}}$. In the heterodimers involving fluorine derivatives (FCl, FBr and $\mathbf{F I}$ ) the strongest interactions correspond to $\mathbf{5 b}$ and $\mathbf{6 a}$, in which $\pi$-hole interactions through the $\pi$-hole over the $\mathrm{N}$ atom in $\mathrm{FNO}_{2}$ occurred, the $\mathrm{Y}$ or $\mathrm{O}$ atom $\left(\mathrm{YNO}_{2}\right)$ acted as the electron donor. This is consistent with the previously mentioned MEP values which indicate that $\mathrm{FNO}_{2}$ shows the most positive MEP value over the $\mathrm{N}$ atom ( 0.0590 a.u.), and therefore, it should be expected that those complexes involving a donation into the $\mathrm{N} \pi$-hole would present the largest negative $E_{\mathrm{b}}$. In the rest of compounds, $E_{\mathrm{b}}\left(\mathbf{C l B r}_{\mathbf{2 a}}\right)$ is the most negative $\left(-5.50 \mathrm{~kJ} \mathrm{~mol}^{-1}\right)$ with $\mathbf{C l B r}_{3 \mathrm{a}-\mathrm{b}}$ and $\mathbf{C l B r}_{6 \mathrm{a}}$ at $0.1 \mathrm{~kJ} \mathrm{~mol}^{-1}$ and $0.2 \mathrm{~kJ} \mathrm{~mol}^{-1}$, respectively. In ClI and BrI, compounds $\mathbf{3 b}$ and $\mathbf{4 b}$ present the highest interaction energies. Curiously, compound $\mathbf{3 a}(\mathbf{b})$ shows a parallel disposition of the molecules (i.e., both molecular planes are parallel) whereas in $\mathbf{5 a}(\mathbf{b})$ both planes are perpendicular. In $\mathbf{C l I}_{\mathbf{3 b}}$ and $\mathbf{B r I}_{3 \mathbf{b}}$, the molecules interact more strongly $\left(-10.4 \mathrm{~kJ} \mathrm{~mol}^{-1}\right.$ and $-10.8 \mathrm{~kJ} \mathrm{~mol}^{-1}$ ) than is observed for $\mathbf{C l I}_{\mathbf{5 b}}$ and $\mathbf{B r I}_{5 \mathbf{b}}$ $\left(-9.2 \mathrm{~kJ} \mathrm{~mol}^{-1}\right.$ and $\left.-9.6 \mathrm{~kJ} \mathrm{~mol}^{-1}\right)$, with up to $1.2 \mathrm{~kJ} \mathrm{~mol}^{-1}$ difference, which indicates that parallel structures are favoured.

\section{Electronic properties}

The electron density $\left(\rho_{\mathrm{BCP}}\right)$ of the different complexes was determined using the atoms in molecules (AIM) theory and the molecular graphs which were generated of all the interactions within the complexes are shown in the Table S1 (ESI $\dagger$ ). Table S2 $(\mathrm{ESI} \dagger)$ summarizes the electron density at the $\mathrm{BCP}\left(\rho_{\mathrm{BCP}}\right)$ and the Laplacian $\left(\nabla^{2} \rho_{\mathrm{BCP}}\right)$ values for each interaction.

As observed, four different types of interactions were found within $\mathrm{XNO}_{2}: \mathrm{YNO}_{2}$ complexes all of them characterized by the existence of a BCP and a bond path connecting two atoms. These interactions were: halogen bonds between both halogen atoms, $\mathrm{X} \cdots \mathrm{Y}, \pi$-hole interactions in which the halogen $\mathrm{X}$ or $\mathrm{Y}$ atom of one molecule acts as a electron donor and $\mathrm{N}$ atom as an acceptor, $\mathrm{X} \cdots \mathrm{N}$, chalcogen bonds between oxygen atoms of both moieties, $\mathrm{O} \cdots \mathrm{O}, \mathrm{X} \cdots \mathrm{O}$ interactions in which the oxygen is interacting with the $\mathrm{X}$ atoms through the $\sigma$-hole.
Complexes 1a and $\mathbf{1 b}$ are characterized either by a single halogen bond or by a halogen bond plus one $\mathrm{X} \cdots \mathrm{O}$. However, in those $\mathrm{X} \cdots \mathrm{O}$ interactions found using AIM, $\mathrm{X}$ and $\mathrm{O}$ atoms are longer than the sum of their van der Waals (vdW) radii, thus these $\mathrm{X} \cdots \mathrm{O}$ contacts cannot be classified as charge transfer interactions. Complexes 2a are stabilized by different type of interactions, $\mathbf{F C l}_{2 \mathbf{a}}$ shows $\mathrm{F} \cdots \mathrm{N}, \mathrm{Cl} \cdots \mathrm{N}$ and additional $\mathrm{O} \cdots \mathrm{O}$ interactions, whereas in $\mathbf{F B r}_{2 \mathrm{a}}$ only $\mathrm{F} \cdots \mathrm{N}$ and $\mathrm{O} \cdots \mathrm{O}$ interactions are present. In the $\mathbf{F I}_{2 \mathrm{a}}$ complex, no $\pi$-hole interaction was found but $\mathrm{F} \cdots \mathrm{I}$ and $\mathrm{O} \cdots \mathrm{O}$ interactions were. However, the distance between $\mathrm{F}$ and $\mathrm{I}$ is $3.592 \AA$, which is greater than the sum of the vdW radii $(3.45 \AA) .{ }^{69}$ The rest of the $2 \mathrm{a}$ complexes show a similar number and type of interactions, $\mathrm{X} \cdots \mathrm{N}, \mathrm{Y} \cdots \mathrm{N}, \mathrm{X} \cdots \mathrm{Y}$ and $\mathrm{O} \cdots \mathrm{O}$ interactions. Nevertheless, the $\mathrm{X} \cdots \mathrm{Y}$ interactions found were not classified as stabilizing interactions because the interacting distance is as stated previously, longer that the sum of the vdW radii. In complexes $\mathbf{2 b}$, fluorine derivatives, $\mathbf{F C l}_{2 \mathbf{b}}, \mathbf{F B r}_{\mathbf{2 b}}$ and $\mathbf{F I}_{\mathbf{2 b}}$ present different interactions: FCl (two $\pi$-holes $\mathrm{X} \cdots \mathrm{N}$ and $\mathrm{Y} \cdots \mathrm{N}$ ), $\mathbf{F B r}$ (a single $\mathrm{Br} \cdots \mathrm{N}$ interaction) and $\mathbf{F I}(\mathrm{F} \cdots \mathrm{N}$ and $\mathrm{F} \cdots \mathrm{I}$ contacts, and the last one is $0.14 \AA$ longer than the sum of the vdW radii),

Table 2 Maxima and minima values of the distance between interacting atoms $\left(R\right.$ in $\AA$ ) electron density ( $\rho$ in a.u.), Laplacian $\left(\nabla^{2} \rho\right.$ in a.u.), total electron energy density ( $H$ in a.u.) at the BCP at the MP2/aug-cc-pVTZ computational level. Correlation coefficients $\left(R^{2}\right)$ for exponential correlation between different quantities have been included

\begin{tabular}{llllll}
\hline & $\mathrm{X} \cdots \mathrm{Y}$ & $\mathrm{X} \cdots \mathrm{N}$ & $\mathrm{O} \cdots \mathrm{O}$ & $\mathrm{X} \cdots \mathrm{O}$ & $\mathrm{O} \cdots \mathrm{N}$ \\
\hline$R_{\min }$ & 2.999 & 2.844 & 3.066 & 3.064 & 2.945 \\
$R_{\max }$ & 4.197 & 3.757 & 3.369 & 3.761 & 3.037 \\
$\rho_{\min }$ & 0.0042 & 0.0040 & 0.0030 & 0.0029 & 0.0056 \\
$\rho_{\max }$ & 0.0130 & 0.0073 & 0.0058 & 0.0111 & 0.0073 \\
$\nabla^{2} \rho_{\min }$ & 0.0128 & 0.0158 & 0.0134 & 0.0112 & 0.0271 \\
$\nabla^{2} \rho_{\max }$ & 0.0485 & 0.0388 & 0.0259 & 0.0436 & 0.0345 \\
$H_{\min }$ & 0.0006 & 0.0010 & 0.0006 & 0.0006 & 0.0016 \\
$H_{\max }$ & 0.0017 & 0.0022 & 0.0014 & 0.0019 & 0.0020 \\
$\operatorname{Exp} . R^{2}(R v s . \rho)$ & 0.57 & 0.82 & 0.92 & 0.65 & 0.55 \\
Exp. $R^{2}\left(R v s . \nabla^{2} \rho\right)$ & 0.71 & 0.96 & 0.93 & 0.82 & 0.78 \\
Exp. $R^{2}(R$ vs. $H)$ & 0.44 & 0.88 & 0.87 & 0.83 & 0.62
\end{tabular}


whereas in ClF, ClI and BrI similar interactions $(\mathrm{X} \cdots \mathrm{N}, \mathrm{Y} \cdots \mathrm{N}$ and $\mathrm{X} \cdot \mathrm{YY}$ ) are found to be characterized by the presence of a BCP. Again, as it occurs in complexes $2 \mathrm{a}$, those $\mathrm{X} \cdots \mathrm{Y}$ contacts are not categorized as stabilizing interactions.

Complexes $\mathbf{F B r}_{3 \mathbf{a}}$ and $\mathbf{F I}_{\mathbf{3 a}}$ show $\mathrm{F} \cdots \mathrm{N}$ ( $\pi$-hole) interactions with a BCP and bond path connecting both atoms, in addition to two parallel $\mathbf{O} \cdots \mathrm{O}$ interactions. However, in $\mathbf{F C l}_{\mathbf{3 a}}, \mathbf{C l B r}_{\mathbf{3 a}}$, $\mathrm{ClI}_{3 \mathbf{a}}$ and BrI $_{3 \mathbf{a}}$ complexes, the BCP connecting $\mathrm{X}$ and $\mathrm{N}$ is not present. Furthermore, those BCPs are not even found in any of the complexes $\mathbf{3 b}$, except for $\mathbf{F I}_{\mathbf{3} \mathbf{b}}$. Instead $\mathrm{X} \cdots \mathrm{O}$ interactions are revealed.

Complexes $\mathbf{4 a}$ and $\mathbf{4 b}$ are characterized by the presence of a single BCP between the oxygen atom of moiety $\mathrm{X}(\mathrm{Y})$ and the corresponding halogen atom of the opposite monomer $\mathrm{Y}(\mathrm{X}) \mathrm{NO}_{2}$. For complexes $\mathbf{5 a}$ and $\mathbf{5 b}$, similar interactions are found to those in complexes 2a. $\mathrm{X} \cdots \mathrm{N}$ interactions are only present in half of the cases $\left(\mathbf{F C l}_{\mathbf{5 a}}, \mathbf{C l B r}_{\mathbf{5 a}}, \mathbf{F C l}_{\mathbf{5 b}}, \mathbf{F B r}_{\mathbf{5 b}}, \mathbf{C l B r}_{5 \mathbf{b}}\right.$ and $\left.\mathbf{B r I}_{\mathbf{5 b}}\right)$. Additionally, bifurcated $\mathrm{O} \cdots \mathrm{O}$ interactions are shown involving two oxygen atoms from one monomer and one oxygen atom from the other moiety.

Finally both complexes $\mathbf{6 a}$ and $\mathbf{6 b}$ simultaneously exhibit one $\mathrm{O} \cdots \mathrm{N}$ and bifurcated $\mathrm{O} \cdots \mathrm{O}$ interactions. In all cases, $\mathrm{O} \cdots \mathrm{N}$ distances are shorter than the sum of vdW radii and show BCPs between the interacting atoms.

Distance values, $\rho_{\mathrm{BCP}}, \nabla^{2} \rho$ and total electron density energy, $H$, for all the interactions are summarized in Tables S2-S4 (ESI $\dagger$ ) and maxima and minima values are shown in Table 2. As observed, the $\mathrm{X} \cdots \mathrm{Y}$ interaction distance ranges from $2.999 \AA$ $\left(\mathbf{F I}_{\mathbf{1 b}}\right)$ to $4.197 \AA\left(\mathbf{B r I}_{\mathbf{2 b}}\right)$. In particular, those with shorter $\mathrm{X} \cdots \mathrm{Y}$ distances correspond to $\mathbf{1 a}$ and $\mathbf{1 b}$ complexes, which present a single $\mathrm{X} \cdots \mathrm{Y}$ interaction through the halogen $\sigma$-hole. $\mathrm{X} \cdots \mathrm{N}$ and $\mathrm{O} \cdots \mathrm{N}$ interactions, classified as $\pi$-holes, present distances between 2.844-3.757 $\AA$, showing a wider range than in $\mathrm{X} \cdots \mathrm{Y}$

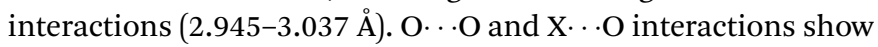
$\mathrm{O} \cdots \mathrm{O}$ and $\mathrm{X} \cdots \mathrm{O}$ distances longer than the sum of the vdW radii, so they are not catalogued as chalcogen interactions, but rather as vdW interactions. For the electron density at the BCPs,

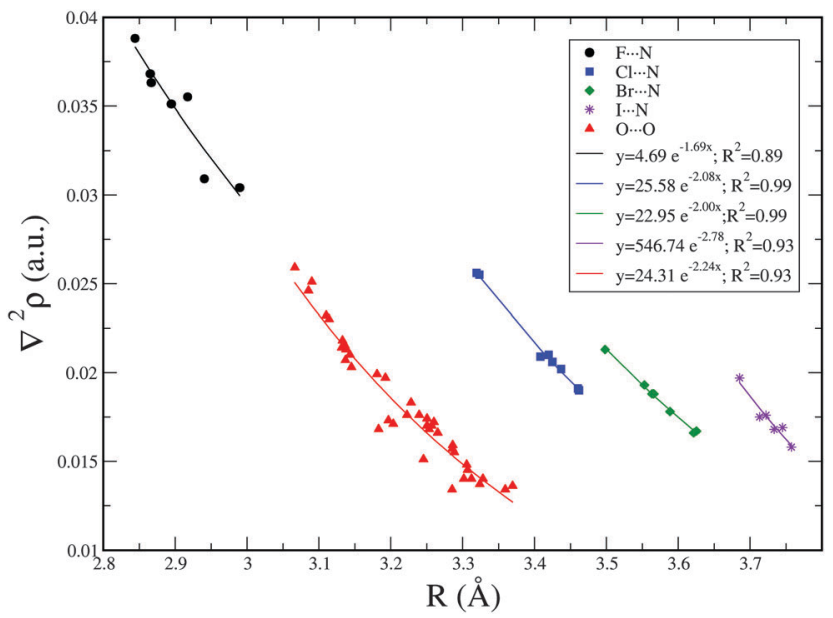

Fig. 3 Exponential relationship between $X \cdots N$ and $O \cdots O$ intermolecular distance $(R)$ and Laplacian of the electron density at the BCP $\left(\nabla^{2} \rho\right)$.

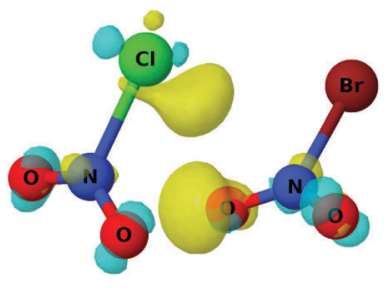

$\mathrm{ClBr}_{3 a}$

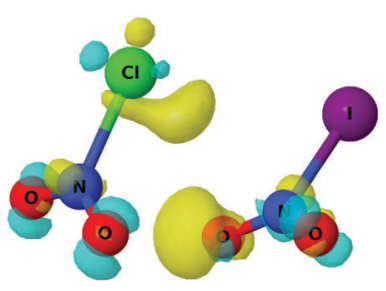

$\mathrm{ClI}_{3 \mathrm{a}}$

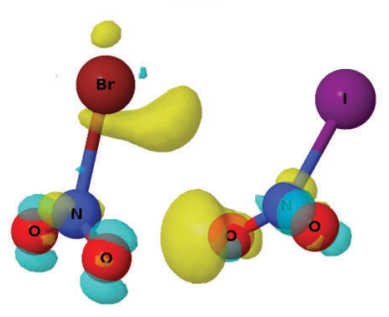

$\mathrm{BrI}_{3 \mathrm{a}}$

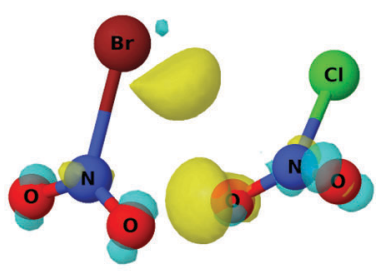

$\mathrm{ClBr}_{3 \mathrm{~b}}$

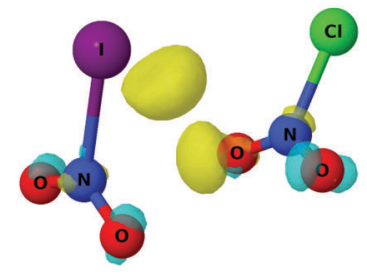

$\mathrm{ClI}_{3 \mathrm{~b}}$

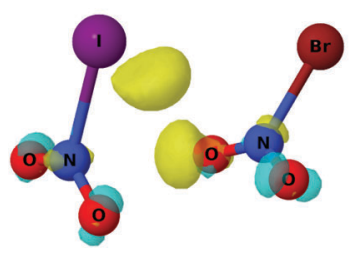

$\mathrm{BrI}_{3 \mathrm{~b}}$
Fig. 4 Electron density shift for $\mathrm{ClBr}_{3 a-b}, \mathrm{Cll}_{3 a-b}$ and $\mathrm{Brl}_{3 \mathbf{a}-\mathbf{b}}$ complexes with an isosurface value of 0.0005 a.u. Yellow (positive) and cyan (negative) areas indicate the increase and decrease of the electron density upon complexation, respectively.

the range observed shows that all the interactions correspond to non-covalent interactions. Special attention should be paid to the $\mathrm{O} \cdots \mathrm{O}$ and $\mathrm{X} \cdots \mathrm{O}$ where values relatively close to 0.002 a.u. are observed, indicating such interactions are within the range of vdW interactions. Laplacian values, $\nabla^{2} \rho$, are positive and range from 0.0058 to 0.0271 a.u., indicating close shell interactions.

In terms of total electron energy density, it has been demonstrated that the sign of the total energy, $H$, defined as $G+V$, is an indicator of the amount of covalence in chemical interactions. $^{70-72}$ Thus, negative $H$ values indicate a significant sharing of electrons. However, $H$ values found within the all complexes are positive which may suggest poor electron sharing between monomers.

Exponential relationships between the Laplacian values, $\nabla^{2} \rho$, at the BCP and the interatomic distance $R$ were found and are shown in Fig. 3 for each family of $\mathrm{X} \cdots \mathrm{N}$, and $\mathrm{O} \cdots \mathrm{O}$ interactions. The best exponential correlations were found for $\mathrm{Cl} \cdots \mathrm{N}$ and $\mathrm{Br} \cdots \mathrm{N}$ interactions with $R^{2}=0.99$. Similar exponential relationships were found between $R$ versus $\rho$ and $R$ versus $\nabla^{2} \rho$ in the $\mathrm{XNO}_{2}$ homodimers and similar non-covalent interactions..$^{8,34,49,73-81}$ Nevertheless, as observed in Table 2, no fair correlations between $\rho$ and interatomic distance have been found, with the exception of the $\mathrm{O} \cdots \mathrm{O}$ interactions where the correlation coefficient $R^{2}$ is 0.92 . 


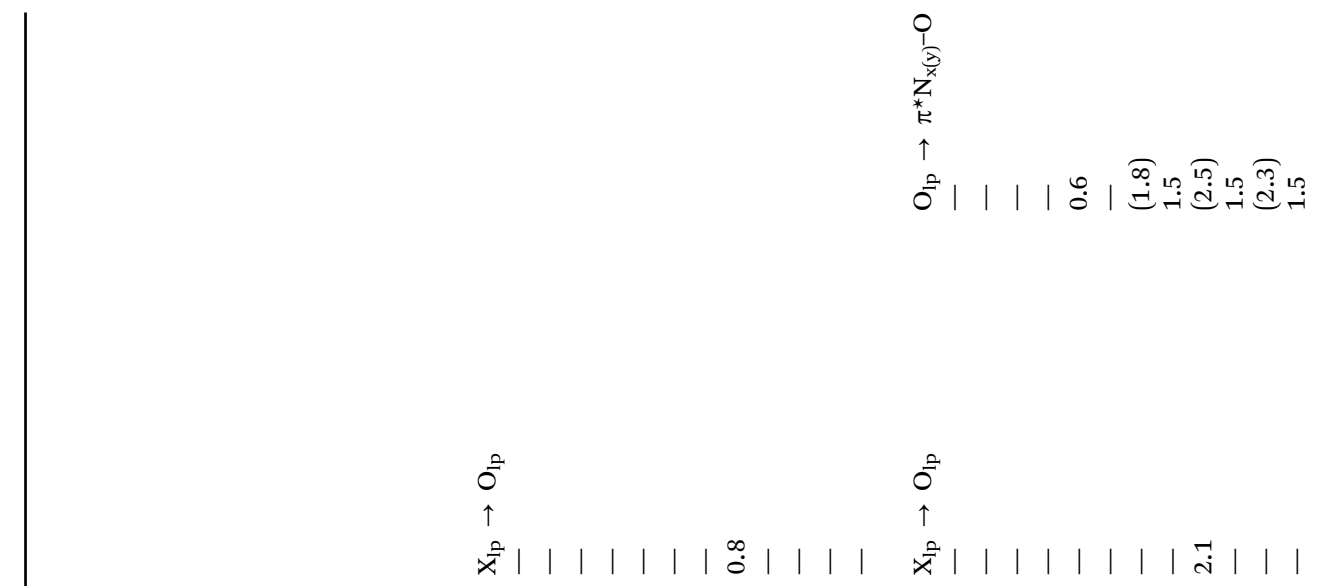

终

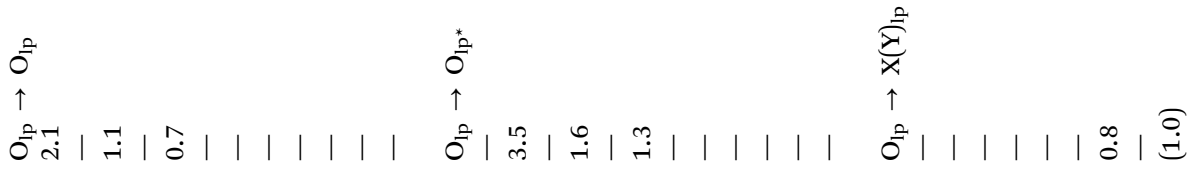

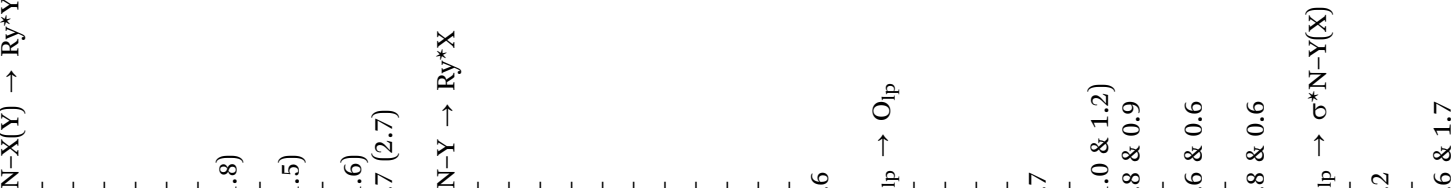

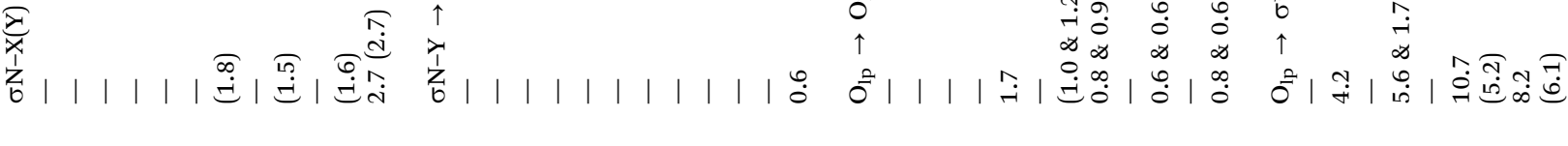

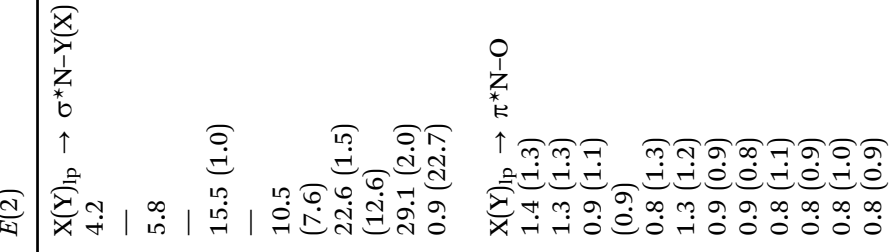

足

\&

等

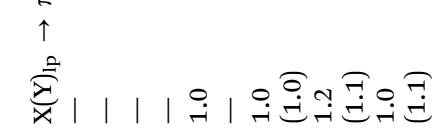

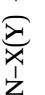


In order to achieve further description of the changes in the electron density upon complexation, electron density shift (EDS) maps were obtained and are shown in Fig. 4 for a set of complexes. The yellow (positive) areas correspond to those regions with an increase of electron density, whereas the cyan (negative) counterparts represent those areas with a loss of electron density upon complexation. As observed in Fig. 3, complexes $\mathbf{C l B r}_{\mathbf{3 a}-\mathbf{b}}, \mathbf{C l I}_{\mathbf{3 a}-\mathbf{b}}$ and $\mathbf{B r I}_{\mathbf{3 a}-\mathbf{b}}$, in which the AIM results show BCPs between oxygen atoms, exhibit a yellow region around the oxygen atom (right-hand monomer) indicating an increase of the electron density on that atom. Additionally, another yellow area is also observed in the halogen atom (lefthand monomer) which again shows evidence of an increase of the electron density generated by the interaction through the halogen atom. Furthermore, small cyan (negative) areas are found in the rest of the oxygen atoms showing a decrease of the electron density and which are consistent with the AIM predictions. However, it is worth noting that the small areas found in addition to the small isodensity value (0.0005 a.u.) indicate very small changes in the electron density upon complexation and therefore very weak interactions in those particular complexes. It is worth noting that similar EDS maps were also found for $\mathrm{XNO}_{2}$ homodimers, which indicates the same nature of each interaction in both homo- and hetero-dimers.

All possible intermolecular interactions between occupied (donor) Lewis-type NBOs and vacant (acceptor) non-Lewis NBOs for the nitryl halide heterodimers have been examined and their energetic importance was estimated using second-order perturbation theory. In Table 3 only the donor-acceptor interactions with second-order perturbation stabilization energies larger than $0.5 \mathrm{~kJ} \mathrm{~mol}^{-1}$ have been included.

According to the NBO analysis, the interaction in $\mathbf{1 a}$ and $\mathbf{1 b}$ complexes is almost exclusively based on a charge donation from a lone pair of electrons of a halogen atom to the vacant antibonding orbital of the sigma bond between the second halogen and nitrogen atoms, the $\sigma$-hole, as derived from the calculated second-order orbital perturbation energies, $E(2)$, listed in Table 3 . These $\sigma$-hole interactions are characteristic of the halogen bonds, which the molecules are entangled in. In fact, these charge-transfer contributions are very large for most of the cases, with increasing energies from the lightest to the heaviest halogen atoms. For example, when $\mathrm{Cl}$ acts as a Lewis acid and $\mathrm{F}, \mathrm{Br}$, and $\mathrm{I}$ as Lewis bases the $E(2)$ values are $4.2,7.6$, and $12.6 \mathrm{~kJ} \mathrm{~mol}^{-1}$, respectively. Similarly, when $\mathrm{Br}$ acts as a Lewis acid $E(2)$ values are $5.8,10.5$, and $22.7 \mathrm{~kJ} \mathrm{~mol}^{-1}$ for $\mathrm{F}$, $\mathrm{Cl}$, and I Lewis bases, respectively, which are substantially larger values than those for the electron acceptor $\mathrm{Cl}$. The largest $E(2)$ values $\left(15.5,22.6\right.$, and $\left.29.1 \mathrm{~kJ} \mathrm{~mol}^{-1}\right)$ are observed for the $\mathrm{lp}(\mathrm{F}, \mathrm{Cl}, \mathrm{Br}) \rightarrow \sigma^{*}(\mathrm{I}-\mathrm{N})$ donor-acceptor contributions, respectively. Complexes with the largest $E(2)$ values correspond to those with the largest binding energies, suggesting that these contributions are significant in such cases. In addition, there are the corresponding back bonding $\sigma$-hole interactions in $\mathbf{F I}_{\mathbf{1 a}}, \mathbf{C l}_{\mathbf{1 a}}, \mathbf{B r I}_{\mathbf{1 a}}$, and BrI $_{\mathbf{1 b}}$, with $E(2)$ values between 0.9 and $2.0 \mathrm{~kJ} \mathrm{~mol}^{-1}$ and, therefore, these are less relevant than the values of their counterparts because their respective $\sigma$-holes are not oriented towards the halogen lone pairs. It is worth mentioning the existence of other charge-transfer contributions of up to $2.7 \mathrm{~kJ} \mathrm{~mol}^{-1}$ that arise from the charge donation from $\mathrm{N}-\mathrm{Y}$ sigma bond to the Rydberg unfilled orbital of halogen $\mathrm{X}$ (Table 3). The main findings of the NBO results are in agreement with the results of the AIM calculations for 1a and 1b complexes that show the existence of one BCP connecting both halogen atoms, corresponding to the halogen bond. However, NBO calculations do not show X - . O charge-transfer interactions, a finding which is in agreement with the AIM analysis that shows that the associated BCP is indicative of proximity.

The NBO analysis of the $\mathbf{2 a}$ and $\mathbf{2 b}$ compounds presents the following general results. Firstly, the main charge-transfer contributions arise from $\pi$-hole contacts where a lone pair of a halogen interacts with a $\pi^{*}$ orbital of an $\mathrm{N}-\mathrm{O}$ bond (Table 3 ) and are common in all complexes. In fact there are not one but two $\pi$-hole contacts, i.e., one where a halogen atom lone pair of the first nitryl halide interacts with the $\pi^{*}(\mathrm{~N}-\mathrm{O})$ orbital of the second nitryl halide, and another one where a halogen atom lone pair of the second nitryl halide interacts with the $\pi^{*}(\mathrm{~N}-\mathrm{O})$ orbital of the first nitryl halide (Table 3, values in parentheses). Secondly, the second-order orbital perturbation energies associated with these $\pi$-hole contacts are very small in comparison to the ones obtained for the $\sigma$-hole halogen bonding interactions in $\mathbf{1 a}$ and $\mathbf{1 b}$ complexes. Indeed the corresponding $E(2)$ values are around $1 \mathrm{~kJ} \mathrm{~mol}^{-1}$. It is worth stressing the existence of other small contributions (from 0.6 to $2.1 \mathrm{~kJ} \mathrm{~mol}^{-1}$ ) that arise from charge donations from a lone pair of an $\mathrm{O}$ atom to a lone pair of another $\mathrm{O}$ atom in fluorine-containing complexes, for example, $\mathbf{F C l}_{2 \mathbf{a}}, \mathbf{F B r}_{2 \mathbf{a}}$, and $\mathbf{F I}_{2 \mathbf{a}}$, from the $\sigma(\mathrm{N}-\mathrm{I})$ orbital to the Rydberg unfilled orbital of $\mathbf{B r}$ in $\mathbf{B r I}_{\mathbf{2 b}}$, and from a lone pair of $\mathrm{Cl}$ to a lone pair of an $\mathrm{O}$ atom in $\mathbf{C l B r}_{2 \mathbf{b}}$. Interestingly, when comparing NBO and AIM results, it was observed that in general both $\pi$-hole contacts were identified by the presence of BCP for $\mathrm{X} \cdots \mathrm{N}$ and $\mathrm{Y} \cdots \mathrm{N}$ interactions for $\mathbf{1 a}$ and $\mathbf{1 b}$ complexes. Furthermore, AIM calculations showed the existence of BCPs between $\mathrm{O}$ atoms, as observed in the NBO study. However, the X...Y long contacts identified by BCPs were not observed in the NBO analysis thus reaffirming that these interactions cannot be categorized as stabilizing.

Compounds $\mathbf{3}$ and $\mathbf{5}$ are characterized by similar chargetransfer interactions because of their geometrical similarity, as derived from the NBO results shown in Table 3. Therefore, these complexes present $\pi$-hole interactions between the $\pi^{*}(\mathrm{~N}-\mathrm{O})$ orbital and a lone pair of a halogen atom, charge donations from a lone pair of an $\mathrm{O}$ atom to a lone pair of another $\mathrm{O}$ atom, which are in general reflected in the AIM results by the presence of BCPs. Furthermore, $\mathbf{3}$ and $\mathbf{5}$ present a lone pair of $\mathrm{Cl}$ interacting with a lone pair of an $\mathrm{O}$ atom only in $\mathbf{C l I}_{\mathbf{3 a}}$ and $\mathbf{C l B r}_{\mathbf{5 a}}$. The AIM results show BCPs for the halogen-oxygen contacts in all complexes suggesting that both atoms are not close enough for charge transfer interactions to occur. In fact only $\mathbf{C l I}_{\mathbf{3 a}}$ and $\mathbf{C l B r}_{\mathbf{5 a}}$ show halogen-oxygen contact distances smaller than the respective sum of their vdW radii. Unlike compounds of $\mathbf{5}$, compounds of 3 , especially those without fluorine, include $\mathrm{O}_{\mathrm{lp}} \rightarrow \pi^{*}(\mathrm{~N}-\mathrm{O})$ donor-acceptor $\pi$-hole contributions. In the same way, compounds 
of 5 (actually only compound 5a) include $Y_{l p} \rightarrow \sigma^{*}(N-X) \sigma$-hole contributions that are not present in compounds of $\mathbf{3}$. In addition, compounds of $\mathbf{5}$ have more $\mathrm{O}_{\mathrm{lp}} \rightarrow \mathrm{O}_{\mathrm{lp}}$ contributions than compounds of $\mathbf{3}$ because oxygen atoms in $\mathbf{5}$ are much closer than in 3. The $E(2)$ values associated with all the previously mentioned interactions are relatively small, around $1 \mathrm{~kJ} \mathrm{~mol}^{-1}$, except for $\mathrm{O}_{\mathrm{lp}} \rightarrow \pi^{*}(\mathrm{~N}-\mathrm{O})$ and $\mathrm{O}_{\mathrm{lp}} \rightarrow \mathrm{O}_{\mathrm{lp}}$ donor-acceptor contributions in 3 and 5 that are as large as 2.5 and $3.7 \mathrm{~kJ} \mathrm{~mol}^{-1}$, respectively. In fact, the latter interactions are slightly larger for $\mathbf{5 b}$ complexes than for 5a complexes. In agreement with the NBO results, the AIM analysis reveals BCPs for these contacts.

Similarly, to compounds $\mathbf{1 a}$ and $\mathbf{1 b}$, compounds $\mathbf{4 a}$ and $\mathbf{4 b}$ exhibit typical halogen bond $\sigma$-hole interactions based on the charge donation from the lone pair of an oxygen atom to a $\sigma^{*}$ orbital of a N-halogen bond, as can be inferred from the $E(2)$ values (Table 3). Similarly, these charge-transfer contributions are large, compared to those observed for compounds 2, 3 and $\mathbf{5 .}$ The larger the halogen atom acting as a Lewis acid the larger the energy contribution, as also observed in compounds $\mathbf{1 a}$ and $\mathbf{1 b}$, although they are larger for the latter than for the former compounds. Thus, the largest $E(2)$ values (15.6 and $17.2 \mathrm{~kJ} \mathrm{~mol}^{-1}$ ) are observed mainly when iodine acts as the halogen bond donor $\left(\mathbf{C l I}_{\mathbf{4 b}}\right.$ and $\mathbf{B r I}_{\mathbf{4 b}}$, respectively). It is interesting to note the presence of other less important contributions with $E(2)$ values up to $1.4 \mathrm{~kJ} \mathrm{~mol}^{-1}$. These charge-transfer phenomena are based, firstly, on the $\mathrm{N}-\mathrm{X}(\mathrm{Y}) \sigma$ bond to a Rydberg unfilled orbital of an oxygen atom donor-acceptor interaction (Table 3) and, secondly, on the oxygen lone pair and a halogen lone pair donor-acceptor interaction, the latter only for complexes of $\mathbf{4 a}$ excluding fluorine and the former only for complexes of $\mathbf{4 b}$ excluding fluorine and $\mathbf{B r I}_{\mathbf{4 a}}$. There is a good agreement between the NBO and AIM calculations where the halogen bond is characterized by the presence of a BCP connecting both atoms involved.

The NBO analysis of compounds $\mathbf{6 a}$ and $\mathbf{6 b}$ shows all the contacts previously noted by the presence of BCPs in the AIM calculations. Therefore, $\mathrm{O}_{\mathrm{lp}} \rightarrow \pi^{*}(\mathrm{~N}-\mathrm{O}) \pi$-hole and $\mathrm{O}_{\mathrm{lp}} \rightarrow \mathrm{O}_{\mathrm{lp}}$ charge-transfer interactions are observed for all complexes. The associated $E(2)$ values for these interactions are relatively small,

Table 4 DF-DFT-SAPT electrostatic, exchange, induction, dispersion and Hartree-Fock higher-order energy contributions ( $E_{\mathrm{el}}, E_{\mathrm{exch}}, E_{\mathrm{i}}, E_{\mathrm{D}}$, and $\delta(\mathrm{HF})$, respectively), and SAPT interaction energy $\left(E_{\text {SAPT }}\right)$ of nitryl halide heterodimers. Energies in $\mathrm{kJ} \mathrm{mol}^{-1}$. Values in parentheses correspond to $b$ compounds

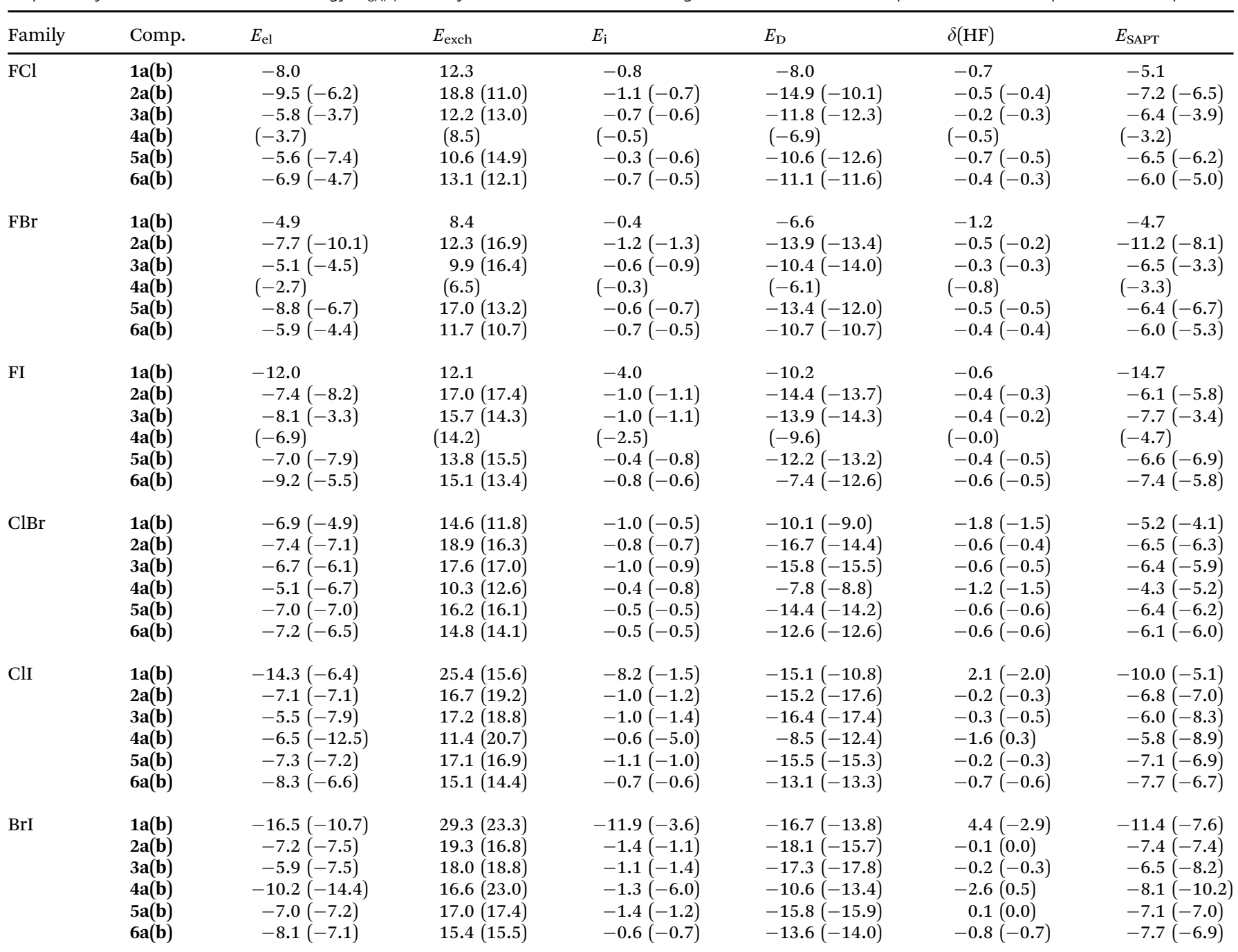



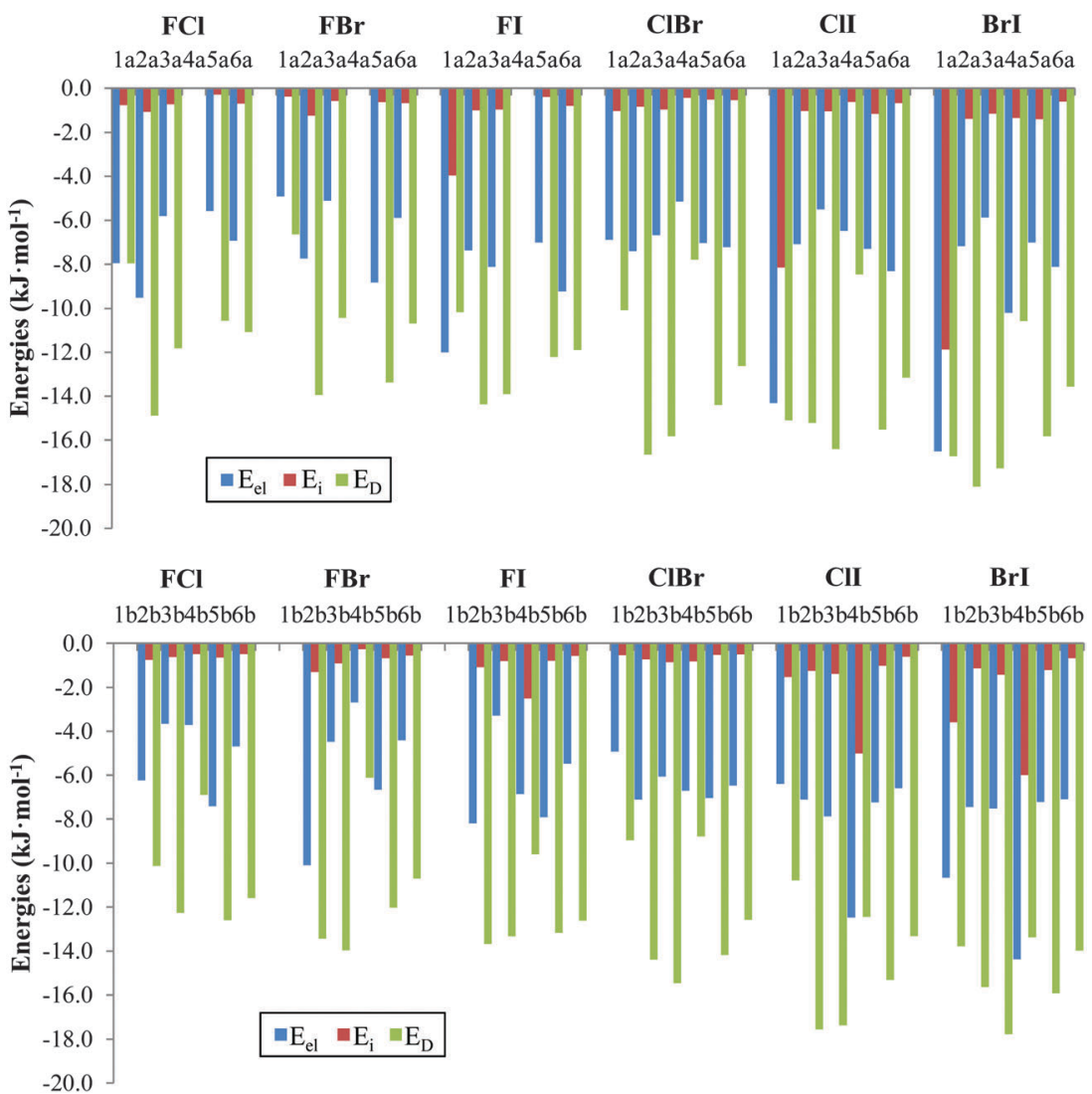

Fig. 5 Graphical representation of the attractive energy contributions in a (top) and b (bottom) complexes using the SAPT-DFT partitioning scheme (see text for details).

in line with those previously reported for compounds 2,3 , and 5. Thus, $E(2)$ values for the $\pi$-hole contribution are approximately $1.5 \mathrm{~kJ} \mathrm{~mol}^{-1}$, whereas more diverse values are obtained for the $\mathrm{O}_{\mathrm{lp}} \rightarrow \mathrm{O}_{\mathrm{lp}}$ contribution, ranging from 0.9 to $2.9 \mathrm{~kJ} \mathrm{~mol}^{-1}$.

The total charge transfer was evaluated using NBO methodology (Table S5, ESI $\dagger$ ). Complexes 2a and 2b, which exhibit symmetrical interaction between both monomers, do not present charge transfer between them. As expected, the largest charge transfers are observed for complexes with the largest $E(2)$ values, i.e., 1 and 4, with a maximum for $\operatorname{BrI}_{1 \mathrm{a}}(-0.04 e)$. In complexes 3 and $\mathbf{5}$, a very similar charge transfer occurs which is in agreement with the $E(2)$ orbital interaction energies. Furthermore, charge transfer is larger for 3a and 5a complexes (0.0015-0.0035 e) than for $\mathbf{3 b}$ and $\mathbf{5 b}$ complexes (0.0001-0.0016 e). This is in agreement with the type of interaction found and the AIM and NBO results. Similarly, complex 6 shows a charger transfer ranging from 0.0002 to $0.0046 e$, which is larger for $\mathbf{6 a}$ than for $\mathbf{6 b}$.

The physical nature of the interaction in the nitryl halide heterodimers was determined using SAPT-DFT calculations. The energy contributions obtained from the SAPT partitioning scheme are listed in Table 4 and the corresponding attractive terms are shown in Fig. 5. In general, the dispersion component, $E_{\mathrm{D}}$, is the largest attractive contributor to the interaction with values ranging from $-6.1\left(\mathbf{F B r}_{\mathbf{4 b}}\right)$ to $-18.1\left(\mathbf{B r I}_{\mathbf{2}}\right) \mathrm{kJ} \mathrm{mol}^{-1}$. Of the total attractive forces the dispersion term varies from $37.1 \%$ $\left(\mathbf{B r I}_{\mathbf{1 a}}\right)$ to $76.6 \%\left(\mathbf{F I}_{3 \mathbf{b}}\right)$. The electrostatic contribution, $E_{\text {el }}$, is the second term in importance with values ranging from $-2.7\left(\mathbf{F B r}_{\mathbf{4 b}}\right)$ to $-16.5\left(\mathbf{B r I}_{1 \mathbf{a}}\right) \mathrm{kJ} \mathrm{mol}^{-1}$. The relative weight of the electrostatic term within all the attractive forces varies from $18.8 \%\left(\mathbf{F I}_{\mathbf{3 b}}\right)$ to $47.7 \%\left(\mathbf{F C l}_{1 \mathbf{a}}\right)$. In fact this term becomes the most important contribution, overcoming the dispersion term, in three $\sigma$-hole based complexes that contain iodine as electron acceptor, namely, $\mathbf{F I}_{\mathbf{1 a}}, \mathbf{C l I}_{\mathbf{4 b}}$ and $\mathbf{B r I}_{\mathbf{4 b}}$. However, the induction term is very small and more or less constant (usually from -0.3 to $-1.5 \mathrm{~kJ} \mathrm{~mol}^{-1}$ ). Exceptions are the halogen bonded complexes $\mathbf{F I}_{\mathbf{4 b}}, \mathbf{B r I}_{\mathbf{1 b}}, \mathbf{F I}_{\mathbf{1 a}}$, $\mathbf{C l I}_{\mathbf{4 b}}, \mathbf{B r I}_{4 \mathrm{~b}}$, and $\mathbf{B r I}_{\mathbf{1 a}}$ with induction energies of $-2.5,-3.6,-4.0$, $-5.0,-6.0,-8.2$, and $-11.9 \mathrm{~kJ} \mathrm{~mol}^{-1}$ which never overcome either the dispersion or electrostatic terms. All in all, the induction term varies from $1.8 \%\left(\mathbf{F C l}_{\mathbf{5 a}}\right)$ to $26.3 \%\left(\mathbf{B r I}_{\mathbf{1 a}}\right)$ of the total attractive forces.

Next, all the compounds of the series will be considered separately. In the halogen bonded complexes $\mathbf{1}$ and $\mathbf{4}$, all three attractive terms have their own importance depending on which complex is being studied. For example, in $\mathbf{F Y}_{\mathbf{1 a}}, \mathbf{C l I}_{\mathbf{1 a}}$, and $\mathbf{B r I}_{\mathbf{1 a}}$ and $\mathbf{C l I}_{\mathbf{4 b}}, \mathbf{B r I}_{\mathbf{4 a}}$, and $\mathbf{B r I}_{\mathbf{4 b}}$ complexes the electrostatic contribution is very similar to the dispersion contribution. As a general trend the relative importance of the electrostatic contribution increases as the atoms become heavier, leading to cases where the electrostatic term is even somewhat larger than the dispersion term $\left(\mathbf{C l I}_{\mathbf{4 b}}\right.$ and $\left.\mathbf{B r I}_{\mathbf{4 b}}\right)$. For the rest of the complexes the dispersion term is always larger than the electrostatic term. However, the induction contribution is generally 
small except for the previously mentioned cases of $\mathbf{F I}_{\mathbf{1 a}}$ $\left(-4.0 \mathrm{~kJ} \mathrm{~mol}^{-1}\right), \mathbf{C l I}_{4 \mathbf{b}}\left(-5.0 \mathrm{~kJ} \mathrm{~mol}^{-1}\right), \mathbf{B r I}_{\mathbf{4 b}}\left(-6.0 \mathrm{~kJ} \mathrm{~mol}^{-1}\right)$, $\mathbf{C l I}_{\mathbf{1 a}}\left(-8.2 \mathrm{~kJ} \mathrm{~mol}^{-1}\right)$ and $\mathbf{B r I}_{\mathbf{1 a}}\left(-11.9 \mathrm{~kJ} \mathrm{~mol}^{-1}\right)$, in other words, for those complexes where the iodine atom (the one with the largest $\sigma$-hole) acts as a Lewis acid. Even in the most ideal situation, $\mathbf{B r I}_{\mathbf{1 a}}$, the induction contribution represents only $26.3 \%$ of all the attractive forces.

For the rest of the complexes, 2, 3, 5, and 6, the induction contribution is significantly small, ranging from $-0.3 \mathrm{~kJ} \mathrm{~mol}^{-1}$ to $-1.4 \mathrm{~kJ} \mathrm{~mol}^{-1}$, representing between $1.8 \%$ and $5.7 \%$ of all the attractive forces, respectively. Because this term is almost negligible it has not been taken into consideration for the following discussion. In compounds $\mathbf{2 a}$ and $\mathbf{2} \mathbf{b}$, the dispersion term is twice as large as the electrostatic contribution, with the exception of the $\mathbf{F Y}_{\mathbf{2 b}}$ compounds where the electrostatic term is slightly lower than the dispersion one. Similarly, in compounds 5 and $\mathbf{6}$ the dispersion term is twice the electrostatic contribution, with the exception of $\mathbf{F I}_{\mathbf{6 a}}$ where the latter is slightly lower than the former. Lastly, the most important dispersion contribution is found in the series of $\mathbf{3 a}$ and $\mathbf{3 b}$ compounds, $\mathbf{F Y}_{\mathbf{3 b}}, \mathbf{C l I}_{\mathbf{3 a}}$, and $\mathbf{B r I}_{\mathbf{3 a}}$, which is three times as large as the electrostatic term, reaching relative weights of $76.6 \%$ for $\mathbf{F I}_{\mathbf{3 b}}$. For the rest of the compounds of $\mathbf{3}$, the dispersion contribution is approximately double the value of the electrostatic one. The $\delta(\mathrm{HF})$ term in general is very small and only significant values are obtained $\left(>2 \mathrm{~kJ} \mathrm{~mol}^{-1}\right)$ for $\mathbf{C l I}_{\mathbf{1 a}}\left(2.1 \mathrm{~kJ} \mathrm{~mol}^{-1}\right), \mathbf{B r I}_{\mathbf{1 a}}$ $\left(4.4 \mathrm{~kJ} \mathrm{~mol}^{-1}\right)$, and $\mathbf{B r I}_{\mathbf{1 b}}\left(-2.9 \mathrm{~kJ} \mathrm{~mol}^{-1}\right)$, as would be expected for the complexes with the highest induction contributions.

\section{Conclusions}

In summary, the interaction between two units of different nitryl halides have been studied using SCS-RI-MP2 and $\operatorname{CCSD}(\mathrm{T})$ calculations. As a result, a total of 66 nitryl halide heterodimers were obtained which were divided into six families of complexes according to the interactions involved and how the molecules were arranged. Initially 72 heterodimers could be expected, 12 for each group. However, six of these complexes where fluorine acts as a halogen bond donor could not be obtained because fluorine lacks the $\sigma$-hole in $\mathrm{NO}_{2} \mathrm{~F}$.

$\mathrm{XNO}_{2}$ dimers have shown different types of interactions simultaneously which show the flexibility of $\mathrm{XNO}_{2}$ molecules to adopt different configurations upon complexation. These interactions have been categorized as halogen bonds with different donors $\mathrm{X} \cdots \mathrm{Y}$ and $\mathrm{O} \cdots \mathrm{X}$, chalcogen bonds $\mathrm{O} \cdots \mathrm{O}$ and $\pi$-hole interactions $\mathrm{X} \cdots \mathrm{N}$.

The binding energy for the series of dimers varies between -0.6 and $-11.1 \mathrm{~kJ} \mathrm{~mol}^{-1}$. In general, the strongest complexes were those exhibiting halogen or $\pi$-hole interactions in which the more electronegative atoms are located in the donor and acceptor moiety, respectively. This is explained in terms of the electrostatic nature of the $\sigma$-holes (halogen bonds) or $\pi$-holes. In the former, the acceptor moiety bears the more polarizable atom (Y) and therefore the $\sigma$-hole is deeper than in the donor moiety (X). In the latter, it is the larger electronegativity of the halogen atom $\left(\mathrm{XNO}_{2}\right)$, which withdraws a larger electron density from the $\mathrm{N}$ site, making the $\pi$-hole deeper than in $\mathrm{YNO}_{2}$.

In absolute terms complexes $\mathbf{F B r}$ and $\mathbf{C l B r}$ have the least negative interaction energies and the general trend obtained was that the heavier the halogen atoms, the larger the interactions energies. Therefore, the larger binding energies are found for BrI complexes, specifically for the halogen bonded $\mathbf{B r I}_{\mathbf{4 b}}$.

The AIM analysis confirmed the four different types of interactions for the series of complexes. In those complexes with only halogen bonds (complexes 1 and 4), Laplacian and electron density at the bond critical points increase with the size of the halogen atom and this was considered to be indicating a relationship between the interaction energies and the electron density at the BCP. For the rest of the complexes similar values were obtained for the $\mathrm{X} \cdots \mathrm{N}, \mathrm{Y} \cdots \mathrm{N}$, and $\mathrm{N} \cdots \mathrm{O} \pi$-hole interactions. No trend was observed for the chalcogen interactions. Furthermore, exponential relationships were found between Laplacian values and interatomic distances for $\pi$-hole $\left(R^{2}=0.96\right)$ and chalcogen $\left(R^{2}=0.93\right)$ interactions, confirming their non-covalent character.

In general the NBO results were in agreement with the AIM calculations. Thus, the NBO analysis shows that the largest second-order perturbation stabilization energies were observed for the halogen bonds in complexes $\mathbf{1}$ and $\mathbf{4}$, ranging from 0.9 to $29.1 \mathrm{~kJ} \mathrm{~mol}^{-1}$. Within these complexes, the largest $E(2)$ values corresponded to those with the largest binding energies, suggesting that these contributions were significant. Charge transfer between monomers indicated that complexes based on halogen bonds ( $\mathbf{1}$ and $\mathbf{4}$ ) presented the largest charge transfer of all the complexes studied indicating the electrostatic importance in these types of interactions, which was again in agreement with the mentioned strength.

Furthermore, the energy terms obtained from the SAPT partitioning scheme confirmed that the dispersion is the largest attractive contributor to the interaction, varying from $37.1 \%\left(\mathbf{B r I}_{\mathbf{1 a}}\right)$ to $76.6 \%\left(\mathbf{F I}_{\mathbf{3 b}}\right)$ of the attractive forces. These values indicated that despite the fact that the halogen bonds are mainly governed by electrostatic interactions, in those complexes with different types of interactions acting simultaneously, the dispersion played the most important role. This was also supported by the small interaction energies found. However, the electrostatic contribution was the second term of importance varying from $18.8 \%\left(\mathbf{F I}_{3 \mathbf{b}}\right)$ to $47.7 \%\left(\mathbf{F C l}_{\mathbf{1 a}}\right)$, and only surpassing the effect of the dispersion term for three halogenbonding complexes $\left(\mathbf{F I}_{\mathbf{1 a}}, \mathbf{C l I}_{\mathbf{4 b}}\right.$ and $\left.\mathbf{B r I}_{\mathbf{4 b}}\right)$ in which pure halogen bonds are governed by electrostatic interactions. The induction term is very small and never overcomes either the dispersion or electrostatic terms.

\section{Acknowledgements}

We gratefully acknowledge support from the Ministerio de Economía y Competitividad (MINECO), (projects CONSOLIDERIngenio 2010 CSD2010-0065, Fondo Europeo de Desarrollo Regional (FEDER) funds and projects No. CTQ2015-63997-C2-2-P and 
CTQ2014-57393-C2-1-P) and the Comunidad Autónoma de Madrid (S2013/MIT-2841, Fotocarbon). Goar Sánchez-Sanz thanks the Human Frontier Science Program (Project Reference: LT001022/ 2013-C) for their support. David Quiñonero thanks the MINECO of Spain for a "Ramón y Cajal" contract. We thank TCHPC (TCD, Ireland), the Irish Centre for High-End Computing (ICHEC), for the provision of computational facilities and support. Thanks are given to the CTI (CSIC), CCC-UAM, and CESGA for the allocation of computer time.

\section{References}

1 K. Müller-Dethlefs and P. Hobza, Chem. Rev., 2000, 100, 143-168.

2 Halogen Bonding: Fundamentals and Applications, ed. P. Metrangolo and G. Resnati, Springer, Berlin, 2008.

3 I. Rozas, I. Alkorta and J. Elguero, Chem. Phys. Lett., 1997, 275, 423-428.

4 I. Alkorta, I. Rozas and J. Elguero, J. Phys. Chem. A, 2001, 105, 743-749.

5 A. Bauzá, T. J. Mooibroek and A. Frontera, Angew. Chem., Int. Ed., 2013, 52, 12317-12321.

6 S. J. Grabowski, Phys. Chem. Chem. Phys., 2014, 16, 1824-1834.

7 G. Sánchez-Sanz, C. Trujillo, I. Alkorta and J. Elguero, ChemPhysChem, 2012, 13, 496-503.

8 G. Sánchez-Sanz, I. Alkorta and J. Elguero, Mol. Phys., 2011, 109, 2543-2552.

9 L. Azofra, I. Alkorta and S. Scheiner, Theor. Chem. Acc., 2014, 133, 1-8.

10 P. Sanz, M. Yáñez and O. Mó, Chem. - Eur. J., 2003, 9, 4548-4555.

11 S. Scheiner, J. Chem. Phys., 2011, 134, 094315.

12 M. Solimannejad, M. Gharabaghi and S. Scheiner, J. Chem. Phys., 2011, 134, 024312.

13 S. Zahn, R. Frank, E. Hey-Hawkins and B. Kirchner, Chem. Eur. J., 2011, 17, 6034-6038.

14 S. Scheiner, Phys. Chem. Chem. Phys., 2011, 13, 13860-13872.

15 S. Scheiner, CrystEngComm, 2013, 15, 3119-3124.

16 S. Scheiner and U. Adhikari, J. Phys. Chem. A, 2011, 115, 11101-11110.

17 U. Adhikari and S. Scheiner, J. Phys. Chem. A, 2012, 116, 3487-3497.

18 U. Adhikari and S. Scheiner, Chem. Phys. Lett., 2012, 532, 31-35.

19 S. Scheiner, Chem. Phys. Lett., 2011, 514, 32-35.

20 S. Scheiner, J. Chem. Phys., 2011, 134, 164313.

21 U. Adhikari and S. Scheiner, J. Chem. Phys., 2011, 135, 184306.

22 Q.-Z. Li, R. Li, X.-F. Liu, W.-Z. Li and J.-B. Cheng, J. Phys. Chem. A, 2012, 116, 2547-2553.

23 Q.-Z. Li, R. Li, X.-F. Liu, W.-Z. Li and J.-B. Cheng, ChemPhysChem, 2012, 13, 1205-1212.

24 A. Bauzá, D. Quiñonero, P. M. Deyà and A. Frontera, Phys. Chem. Chem. Phys., 2012, 14, 14061-14066.
25 S. Ghosh, S. Biswas, A. Bauzá, M. Barceló-Oliver, A. Frontera and A. Ghosh, Inorg. Chem., 2013, 52, 7508-7523.

26 H. Zhuo, Q. Li, W. Li and J. Cheng, New J. Chem., 2015, 39, 2067-2074.

27 I. Alkorta, G. Sánchez-Sanz, J. Elguero and J. E. Del Bene, J. Chem. Theory Comput., 2012, 8, 2320-2327.

28 J. E. Del Bene, I. Alkorta, G. Sánchez-Sanz and J. Elguero, Chem. Phys. Lett., 2011, 512, 184-187.

29 J. E. Del Bene, I. Alkorta, G. Sánchez-Sanz and J. Elguero, J. Phys. Chem. A, 2012, 116, 3056-3060.

30 J. E. Del Bene, G. Sánchez-Sanz, I. Alkorta and J. Elguero, Chem. Phys. Lett., 2012, 538, 14-18.

31 J. E. Del Bene, I. Alkorta, G. Sánchez-Sanz and J. Elguero, J. Phys. Chem. A, 2012, 116, 9205-9213.

32 I. Alkorta, G. Sánchez-Sanz, J. Elguero and J. E. Del Bene, J. Phys. Chem. A, 2012, 117, 183-191.

33 J. E. Del Bene, I. Alkorta, G. Sánchez-Sanz and J. Elguero, J. Phys. Chem. A, 2013, 117, 3133-3141.

34 G. Sánchez-Sanz, I. Alkorta, C. Trujillo and J. Elguero, ChemPhysChem, 2013, 14, 1656-1665.

35 I. Alkorta, J. Elguero and J. E. Del Bene, J. Phys. Chem. A, 2013, 117, 10497-10503.

36 S. J. Grabowski, I. Alkorta and J. Elguero, J. Phys. Chem. A, 2013, 117, 3243-3251.

37 J. S. Murray, P. Lane and P. Politzer, Int. J. Quantum Chem., 2007, 107, 2286-2292.

38 A. Mohajeri, A. H. Pakiari and N. Bagheri, Chem. Phys. Lett., 2009, 467, 393-397.

39 P. Politzer, J. Murray and M. Concha, J. Mol. Model., 2008, 14, 659-665.

40 J. Murray, P. Lane, T. Clark, K. Riley and P. Politzer, J. Mol. Model., 2012, 18, 541-548.

41 R. Paulini, K. Müller and F. Diederich, Angew. Chem., Int. Ed., 2005, 44, 1788-1805.

42 M. J. Molina and F. S. Rowland, Nature, 1974, 249, 810-812.

43 R. P. Wayne, Chemistry of Atmospheres, Oxford University Press, Oxford, 1991.

44 F. Schweitzer, P. Mirabel and C. George, J. Atmos. Chem., 1999, 34, 101-117.

45 S. Fickert, F. Helleis, J. W. Adams, G. K. Moortgat and J. N. Crowley, J. Phys. Chem. A, 1998, 102, 10689-10696.

46 R. Lesclaux, F. Caralp, A. M. Dognon and D. Cariolle, Geophys. Res. Lett., 1986, 13, 933-936.

47 M. Solimannejad, V. Ramezani, C. Trujillo, I. Alkorta, G. Sánchez-Sanz and J. Elguero, J. Phys. Chem. A, 2012, 116, 5199-5206.

48 M. Solimannejad, N. Nassirinia and S. Amani, Struct. Chem., 2013, 24, 651-659.

49 G. Sánchez-Sanz, C. Trujillo, M. Solimannejad, I. Alkorta and J. Elguero, Phys. Chem. Chem. Phys., 2013, 15, 14310-14318.

50 C. Trujillo, G. Sanchez-Sanz, I. Alkorta and J. Elguero, New J. Chem., 2015, 39, 6791-6802.

51 S. Roy, A. Bauza, A. Frontera, R. Banik, A. Purkayastha, M. G. B. Drew, B. M. Reddy, S. Balasubramanian, S. Das and S. K. Das, CrystEngComm, 2015, 17, 3912-3916.

52 T. H. Dunning, J. Chem. Phys., 1989, 90, 1007-1023. 
53 D. E. Woon and T. H. Dunning, J. Chem. Phys., 1995, 103, 4572-4585.

54 K. A. Peterson, B. C. Shepler, D. Figgen and H. Stoll, J. Phys. Chem. A, 2006, 110, 13877-13883.

55 A. Halkier, T. Helgaker, P. Jørgensen, W. Klopper and J. Olsen, Chem. Phys. Lett., 1999, 302, 437-446.

56 A. Halkier, W. Klopper, T. Helgaker, P. Jørgensen and P. R. Taylor, J. Chem. Phys., 1999, 111, 9157-9167.

57 T. A. Keith, Version 15.09.27 edn, 2015, pp. TK Gristmill Software, aim.tkgristmill.com.

58 A. E. Reed, L. A. Curtiss and F. Weinhold, Chem. Rev., 1988, 88, 899-926.

59 B. Jeziorski, R. Moszynski and K. Szalewicz, Chem. Rev., 1994, 94, 1887-1930.

60 A. J. Misquitta, R. Podeszwa, B. Jeziorski and K. Szalewicz, J. Chem. Phys., 2005, 123, 214103.

61 A. Hesselmann and G. Jansen, Phys. Chem. Chem. Phys., 2003, 5, 5010-5014.

62 R. Moszynski, Mol. Phys., 1996, 88, 741-758.

63 J. P. Perdew, K. Burke and M. Ernzerhof, Phys. Rev. Lett., 1997, 78, 1396.

64 T. J. Lee, Chem. Phys. Lett., 1993, 216, 194-199.

65 D. C. Frost, S. T. Lee, C. A. McDowell and N. P. C. Westwood, J. Electron. Spectrosc. Relat. Phenom., 1975, 7, 331-347.

66 F. Weigend, Phys. Chem. Chem. Phys., 2002, 4, 4285-4291.

67 F. Weigend, A. Köhn and C. Hättig, J. Chem. Phys., 2002, 116, 3175-3183.

68 H.-J. Werner, P. J. Knowles, F. R. Manby, M. Schütz, P. Celani, G. Knizia, T. Korona, R. Lindh, A. Mitrushenkov, G. Rauhut, T. B. Adler, R. D. Amos, A. Bernhardsson, A. Berning, D. L. Cooper, M. J. O. Deegan, A. J. Dobbyn, F. Eckert, E. Goll,
C. Hampel, A. Hesselmann, G. Hetzer, T. Hrenar, G. Jansen, C. Köppl, Y. Liu, A. W. Lloyd, R. A. Mata, A. J. May, S. J. McNicholas, W. Meyer, M. E. Mura, A. Nicklass, P. Palmieri, K. Pflüger, R. Pitzer, M. Reiher, T. Shiozaki, H. Stoll, A. J. Stone, R. Tarroni, T. Thorsteinsson, M. Wang and A. Wolf, MOLPRO, version 2010.1, a package of ab initio programs.

69 A. Bondi, J. Phys. Chem., 1964, 68, 441-451.

70 D. Cremer and E. Kraka, Croat. Chem. Acta, 1984, 57, 1259-1281.

71 S. Jenkins and I. Morrison, Chem. Phys. Lett., 2000, 317, 97-102.

72 W. D. Arnold and E. Oldfield, J. Am. Chem. Soc., 2000, 122, 12835-12841.

73 G. Sánchez-Sanz, C. Trujillo, I. Alkorta and J. Elguero, Phys. Chem. Chem. Phys., 2012, 14, 9880-9889.

74 O. Knop, R. J. Boyd and S. C. Choi, J. Am. Chem. Soc., 1988, 110, 7299-7301.

75 I. Alkorta, L. Barrios, I. Rozas and J. Elguero, THEOCHEM, 2000, 496, 131-137.

76 O. Knop, K. N. Rankin and R. J. Boyd, J. Phys. Chem. A, 2001, 105, 6552-6566.

77 O. Knop, K. N. Rankin and R. J. Boyd, J. Phys. Chem. A, 2002, 107, 272-284.

78 E. Espinosa, I. Alkorta, J. Elguero and E. Molins, J. Chem. Phys., 2002, 117, 5529-5542.

79 I. Alkorta and J. Elguero, Struct. Chem., 2004, 15, 117-120.

80 T. H. Tang, E. Deretey, S. J. Knak Jensen and I. G. Csizmadia, Eur. Phys. J. D, 2006, 37, 217-222.

81 I. Mata, I. Alkorta, E. Molins and E. Espinosa, Chem. - Eur. J., 2010, 16, 2442-2452. 